\title{
Perspectivas para a Política Fiscal Brasileira
}

Manoel Carlos de Castro Pires ${ }^{*}$

\section{Introdução}

Em virtude da eleição para Presidente da República, o ano de 2006 é o momento adequado para se discutir os rumos da política fiscal; verificar os objetivos não atingidos; avaliar porque as políticas fracassaram e redesenhar as estratégias possíveis.

A política fiscal é o principal instrumento que o Governo Federal tem a sua disposição para enfrentar esse problema. Para contemplar seus objetivos o Governo Federal deve decidir quanto e onde arrecadar e gastar, e como poupar para suavizar as flutuações da economia.

Neste sentido, o artigo busca entender como a política fiscal tem sido implementada e quais desequilíbrios devem ser corrigidos. Para tanto, a próxima seção apresenta a perspectiva atual da política fiscal baseada em um modelo de gastos públicos da Coordenação de Finanças Públicas (CFP) do IPEA, apresentado em Carvalho (2001). Busca-se avaliar o que pode acontecer se a atual política de gastos for mantida. Em seguida, alguns cenários alternativos são apresentados com intuito de avaliar possíveis reformas na atual política fiscal. A quarta seção discute algumas implicações para a administração da dívida pública e, por último, seguem as conclusões.

\section{O atual rumo da política fiscal}

Podemos observar na tabela 1, apresentada a seguir, como devem evoluir os gastos do Governo Central caso a política fiscal mantenha o comportamento médio dos últimos anos. Em primeiro lugar, pode-se notar que o volume de gastos totais em relação ao PIB deverá aumentar em quase 3\%. Qual o item de gastos responsável por tamanho aumento? Os benefícios previdenciários aumentarão de 6,14\% em 2004 até 8,53\% em 2015, uma elevação de 2,3\% do PIB. Os demais itens podem ser considerados estáveis. Um dos mais importantes, o item de pessoal, alcança 5,66\% em 2015 contra 5,27\% em 2004. Além disso, a perspectiva para os investimentos públicos é que eles mantenham uma trajetória pífia.

\footnotetext{
Técnico em Pesquisa do IPEA e doutorando em Economia na UnB. Endereço eletrônico: manoel.pires@ipea.gov.br
} 
Tabela 1. Projeção dos gastos não financeiros do Governo Central* (\%PIB)

\begin{tabular}{|c|c|c|c|c|c|c|c|c|c|c|c|c|}
\hline Itens de Gasto & 2004 & 2005 & 2006 & 2007 & 2008 & 2009 & 2010 & 2011 & 2012 & 2013 & 2014 & 2015 \\
\hline Pessoal & 5,27 & 4,87 & 4,99 & 5,03 & 5,09 & 5,19 & 5,29 & 5,41 & 5,47 & 5,55 & 5,63 & 5,66 \\
\hline Saúde & 1,48 & 1,61 & 1,56 & 1,55 & 1,55 & 1,56 & 1,56 & 1,56 & 1,55 & 1,55 & 1,55 & 1,53 \\
\hline Investimentos & 0,62 & 0,89 & 0,86 & 0,83 & 0,81 & 0,79 & 0,77 & 0,75 & 0,72 & 0,70 & 0,67 & 0,65 \\
\hline Inversões & 0,18 & 0,17 & 0,17 & 0,16 & 0,16 & 0,15 & 0,15 & 0,14 & 0,14 & 0,13 & 0,13 & 0,12 \\
\hline Subsídios & 0,54 & 0,60 & 0,58 & 0,56 & 0,54 & 0,53 & 0,52 & 0,51 & 0,49 & 0,47 & 0,47 & 0,44 \\
\hline ODC & 1,92 & 2,32 & 2,28 & 2,25 & 2,21 & 2,17 & 2,11 & 2,06 & 1,99 & 1,93 & 1,93 & 1,78 \\
\hline Ben. Previd. & 6,14 & 7,33 & 7,58 & 7,79 & 8,04 & 8,20 & 8,34 & 8,47 & 8,51 & 8,55 & 8,55 & 8,53 \\
\hline LOAS RMV & 0,43 & 0,48 & 0,52 & 0,53 & 0,54 & 0,55 & 0,56 & 0,57 & 0,57 & 0,58 & 0,58 & 0,57 \\
\hline Seg.desempreg & 0,42 & 0,42 & 0,42 & 0,41 & 0,41 & 0,41 & 0,40 & 0,40 & 0,39 & 0,38 & 0,38 & 0,37 \\
\hline Abono & 0,08 & 0,09 & 0,10 & 0,11 & 0,12 & 0,13 & 0,14 & 0,14 & 0,15 & 0,15 & 0,15 & 0,15 \\
\hline Out.Benefícios & 0,33 & 0,33 & 0,34 & 0,35 & 0,35 & 0,36 & 0,37 & 0,38 & 0,39 & 0,40 & 0,39 & 0,40 \\
\hline Total de Gastos & 17,42 & 19,13 & 19,4 & 19,57 & 19,83 & 20,03 & 20,2 & 20,38 & 20,37 & 20,38 & 20,39 & 20,21 \\
\hline
\end{tabular}

A partir dessa política de gastos públicos, o que esperar do superávit primário? $\mathrm{O}$ montante de superávit primário deve ser acompanhado da carga tributária. A visão mais simples é a de que a carga tributária será mantida, o que significa dizer que o Governo Central deverá ter disponível em caixa $21 \%$ do PIB. Portanto, o superávit primário do Governo Central se aproximará de 1,6\% do PIB em 2006, reduzindo-se até 2015 quando atinge 0,6\% do PIB, contra os 2,8\% do PIB obtido em 2005.

No cenário básico, o Governo Central teria apenas a opção de aumentar a carga tributária caso quisesse manter o superávit primário nos patamares anteriores. Além disso, mantida a atual política de gastos, uma reforma tributária que tenha como objetivo reduzir a carga de impostos é inviabilizada.

\section{Alternativas possíveis}

Se o Governo Central optar por manter o atual superávit primário, ele deverá fazer alguns ajustes na atual política de gastos. Este artigo contempla quatro itens de ajustes: (i) despesas discricionárias, ii) pessoal, (iii) benefícios previdenciários e (iv) benefícios assistenciais.

O ajuste nas despesas discricionárias (investimentos, inversões e outras despesas de custeio) é o mais comum na política fiscal brasileira. Isto ocorre porque esta é a parte da despesa que não é obrigatória por lei, dando grau de manobra ao Governo. Assim, esta é uma opção para o curto prazo, entretanto, acaba por adiar reformas estruturais. A manutenção dessa estratégia pode levar à uma deterioração da economia no longo prazo. 
A redução nas despesas discricionárias de forma a preservar o superávit primário do Governo Central é de $2 \%$ do PIB. Nessa situação, as despesas discricionárias cairiam para menos de $2 \%$ do PIB. O Investimento público poderia ser marginal, afetando o crescimento de longo prazo.

O ajuste na rubrica de pessoal é feito de forma lenta, pois sua redução só é possível de duas maneiras: evitando a entrada de novos funcionários e reduzindo o crescimento dos salários dos servidores. Essas duas políticas possuem impactos positivos sobre as contas da previdência social. Uma redução na taxa de crescimento da despesa média com servidores públicos em $2 \%$ reduz o montante das despesas rígidas totalizando em 2006, 16,70\% do PIB, o que adicionando às receitas discricionárias mantém o superávit primário do Governo Central abaixo de 1\% do PIB na projeção para 2015. Assim, a redução da despesa média com pessoal deveria ser muito grande para manter a política de superávit primário sem mencionar o impacto dessa política sobre a oferta de bens públicos.

A redução nos benefícios previdenciários é a mais complexa de ser feita, pois seria necessária uma reforma da previdência. Entretanto, este é o ajuste mais estrutural dentre os avaliados. Além disso, nota-se que essa rubrica é a principal responsável pelo aumento dos gastos em relação ao PIB.

Conforme Caetano (2006), a previdência social brasileira tem forte apelo redistributivo. Sendo assim, pode-se dizer que esse é um sistema que nasceu para ser desequilibrado e, portanto, olhar simplesmente para o seu déficit seria superficial. $O$ importante é saber se esse déficit é explosivo. Os dados recentes sugerem que sim, pois as despesas previdenciárias aumentaram 1\% do PIB em quatro anos, enquanto as receitas permaneceram estáveis no mesmo período.

Ao observar as características da previdência brasileira, pode-se observar que o desenho do plano previdenciário brasileiro é bastante peculiar. No caso de aposentadoria por morte, em uma comparação internacional, o Brasil é o único país que não possui exigência de idade mínima, não possui carência contributiva e que permite acumulação plena com outras aposentadorias. É ainda o único país que reajusta as pensões com base no salário mínimo, o que se torna um problema quando esses reajustes superam a inflação. Além disso, a previdência rural brasileira apresenta cobertura de menos de $10 \%$, ou seja, mais de $90 \%$ das aposentadorias pagas não possuem fonte de arrecadação. Conseqüentemente, o déficit da previdência rural é a metade do déficit total, apesar de ser um programa bem menos abrangente. 
Infelizmente, o modelo da Coordenação de Finanças Públicas (CFP) não possui tamanha desagregação que permita uma avaliação quantitativa de todas essas reformas. $\mathrm{O}$ bloco de previdência do modelo avalia apenas os reajustes das pensões e a entrada e saída de pessoas no sistema com base na estimativa passada. Entretanto, essas questões deverão ser atacadas com o objetivo de frear o crescimento dessa rubrica.

O ajuste nos benefícios assistenciais contempla a redução na política social do governo (redução na concessão da bolsa família, por exemplo) e possui impactos equivalentes ao da despesa com pessoal. Entretanto, esse é a principal política do Governo Central, sendo difícil esperar que o ajuste venha por meio desse item.

\section{A trajetória da dívida pública}

Para se avaliar a trajetória da dívida pública é necessária a adoção de algumas hipóteses adicionais, por exemplo, o superávit primário dos demais governos subnacionais, da taxa de juros e da taxa de crescimento da economia. Para os governos subnacionais, assumiuse que esses manterão a média do superávit primário obtido no período 1999/2005 (0,1\% do PIB para municípios e $0,6 \%$ do PIB para os estados). Como taxa de crescimento se adotou $4 \%$ e para a taxa de juros $9 \%$.

No cenário básico, onde se assume que a atual política de gastos públicos será mantida, a dívida pública alcança, após 10 anos, 63,58\% do PIB. Este resultado é obtido a partir da queda do superávit primário, o qual se ajusta às receitas que são tomadas como constantes e a um montante de gastos cada vez maior. No cenário em que se ajustam as despesas discricionárias (redução de 2\%), o investimento público é marginal. A taxa de crescimento econômico foi reduzida para $3 \%$ e a dívida pública atingiu 46,5\% do PIB. No cenário em que a despesa com pessoal foi ajustada, a taxa de crescimento econômico foi mantida em $4 \%$ e a dívida pública alcança $42 \%$ do PIB, sendo este resultado equivalente a um ajuste nos benefícios assistenciais.

\section{Conclusões}

O presente artigo teve como objetivo avaliar as opções de política fiscal para os próximos anos. Como primeiro resultado, nota-se que a possibilidade de uma reforma tributária que reduza a carga tributária é pouco viável. Isso significaria uma grande mudança no estado atual das finanças do Governo Central. Como segundo resultado, nota-se que, tomando a carga tributária como constante, e o atual ritmo das despesas do Governo Central, 
a atual meta de superávit primário não deverá ser atingida nos próximos anos. Neste cenário, a dívida pública se torna crescente.

Em linha com essa conclusão, o Tesouro Nacional, no segundo semestre desse ano, realizou um corte significativo nas despesas discricionárias e isso leva ao ponto fundamental: onde o Governo Central deverá efetuar seus cortes de gastos? Ao discutir as quatro possibilidades, mostrou-se que reduções nas despesas médias com pessoal e reduções nas despesas assistenciais obtêm-se resultados semelhantes. O primeiro resultado é que o superávit primário não alcança 4,25\% do PIB. O segundo resultado é que o superávit primário atingido é suficiente para a redução da dívida pública, a qual alcança $42 \%$ do PIB em 2015.

O cenário que contempla a redução nas despesas discricionárias gera um corte significativo nos investimentos públicos, sendo esse, em termos econômicos, o pior tipo de corte e o mais comum no caso brasileiro. Ao utilizar essa opção, a dívida pública em 2015 deve se situar em torno de 46,5\% do PIB. Ademais, discutiu-se o caso da previdência social que possui inúmeros pontos para reforma. Apesar do modelo atual da CFP não contemplar explicitamente esses itens, acredita-se que a previdência deverá sofrer alguns ajustes como forma de aliviar a atual pressão sobre os investimentos públicos.

Por último, pode-se notar que existem diversos caminhos para a consolidação da política fiscal como instrumento de crescimento econômico, de redução da desigualdade e de sustentabilidade financeira. Os caminhos adotados vão refletir o peso que o Governo dá a esses objetivos. Entretanto, é importante dizer que esses objetivos não são contraditórios entre si.

\section{Referências Bibliográficas}

CAETANO, M. (2006). Determinantes da sustentabilidade e do custo previdenciário: aspectos conceituais e comparações internacionais. IPEA. Mimeo.

CARVALHO, J. C. J. (2001). Tendência de longo prazo das finanças públicas no Brasil. Texto para Discussão, IPEA, no 795. 
